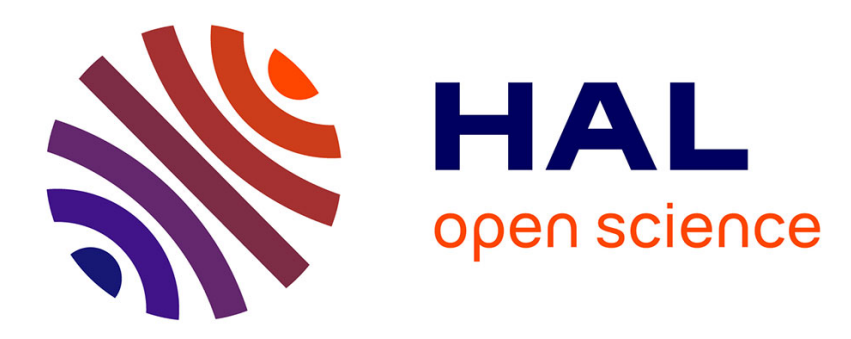

\title{
Diffusion of nitrogen implanted in titanium nitride (TiN1-x)
}

F. Abautret, P. Eveno

\section{To cite this version:}

F. Abautret, P. Eveno. Diffusion of nitrogen implanted in titanium nitride (TiN1-x). Revue de Physique Appliquée, 1990, 25 (11), pp.1113-1119. 10.1051/rphysap:0199000250110111300 . jpa00246281

\section{HAL Id: jpa-00246281 https://hal.science/jpa-00246281}

Submitted on 1 Jan 1990

HAL is a multi-disciplinary open access archive for the deposit and dissemination of scientific research documents, whether they are published or not. The documents may come from teaching and research institutions in France or abroad, or from public or private research centers.
L'archive ouverte pluridisciplinaire HAL, est destinée au dépôt et à la diffusion de documents scientifiques de niveau recherche, publiés ou non, émanant des établissements d'enseignement et de recherche français ou étrangers, des laboratoires publics ou privés. 
Classification

Physics Abstracts

$61.70 \mathrm{~B}-61.80-66.30 \mathrm{H}$

\title{
Diffusion of nitrogen implanted in titanium nitride $\left(\operatorname{TiN}_{1-x}\right)$
}

\author{
F. Abautret and P. Eveno \\ Laboratoire de Physique des Matériaux, C.N.R.S., 1 place Aristide Briand, 92190 Meudon, France
}

(Received 2 April 1990, revised 3 July 1990, accepted 11 July 1990)

\begin{abstract}
Résumé. - La diffusion de l'azote 15 implanté dans des monocristaux de nitrure de titane non stoechiométrique (phase $\delta$ - $\mathrm{TiN}_{1-x}$ ) a été étudiée dans un domaine de température compris entre $700{ }^{\circ} \mathrm{C}$ et $1400{ }^{\circ} \mathrm{C}$. La durée des traitements de diffusion est de l'ordre de 2 heures. Les profils de concentration d'azote 15 , obtenus après implantation et après recuit de diffusion sont mesurés à l'aide d'un analyseur ionique secondaire (SIMS). Les coefficients de diffusion sont déterminés en ajustant sur chaque profil expérimental une courbe théorique correspondant à l'évolution par diffusion d'un profil initial partiellement gaussien. Le coefficient de diffusion de l'azote 15 dans le domaine de température étudié, se traduit par la relation: $D=4 \times 10^{-7}\left(\mathrm{~cm}^{2} / \mathrm{s}\right) \exp [-2,26 \pm 0,2(\mathrm{eV} / \mathrm{at}) / k T]$, dans la région proche de la surface (à forte concentration en traceur) et par la relation : $D=1,3 \times 10^{-8}\left(\mathrm{~cm}^{2} / \mathrm{s}\right) \exp [-1,65 \pm 0,2(\mathrm{eV} / \mathrm{at}) / k T]$ plus en profondeur.
\end{abstract}

\begin{abstract}
The diffusion of nitrogen 15, implanted in non-stoichiometric titanium nitride single-crystals $\left(\delta-\mathrm{TiN}_{1-x}\right.$ phase), was investigated in the $700{ }^{\circ} \mathrm{C}-1400{ }^{\circ} \mathrm{C}$ temperature range. The annealing time was about 2 hours. The concentration profiles of nitrogen 15, after implantation and diffusion annealing, were measured by Secondary Ion Mass Spectrometry (SIMS). The diffusion coefficients were determinated by fitting the experimental and theoretical profiles, corresponding to the solution of the Fick's law for an initial partly Gaussian profile. The diffusion coefficient of nitrogen 15 can be described by the relation: $D=4 \times 10^{-7}\left(\mathrm{~cm}^{2} / \mathrm{s}\right) \exp [-2.26 \pm 0.2(\mathrm{eV} / \mathrm{at}) / k T]$, in the layer near the surface (at high tracer concentration) and by the relation : $D=1.3 \times 10^{-8}\left(\mathrm{~cm}^{2} / \mathrm{s}\right) \exp [-1.65 \pm 0.2(\mathrm{eV} / \mathrm{at}) / k T]$ in a deeper layer.
\end{abstract}

\section{Introduction.}

Titanium nitride is an important technological material of much interest because of its good wear resistance ; it is particularly used as protective coating. But its fundamental properties have received little attention. It has a high melting point $\left(2949^{\circ} \mathrm{C}\right)$ and it is single phased for a large range of composition. Therefore, it is a good material for a study of point defects related to non-stoichiometry. Few studies have been ma e on 1 usion in $\mathrm{n} 1 \mathrm{r} 1$ es compared with the oxides. No data are available about nitrogen (or titanium) diffusion in titanium nitride. Only a few attempts of diffusion coefficient calculations have been made from sintering in polycrystals [1-5]. This lack of data about nitrogen diffusion in titanium nitride can be explained by the fact that it is quite difficult to develop adapted diffusion methods; there is no radioactive isotope with a long enough life time. The gas-solid technique can be used, but it requires a large amount of nitrogen 15 which is very expensive.
Therefore, an alternative method was chosen : ion implantation. This method is of much interest because nitrogen 15 ions can be introduced in small quantity $\left(6 \times 10^{16}\right.$ ions $\left./ \mathrm{cm}^{2}\right)$ and without significant loss.

\section{Experimental procedures.}

2.1 PREPARATION OF SAMPLES. - Single crystals of 1 anium ni ri e $\mathrm{i} 0.82$

materials. They were fabricated by A.N. Christensen (University of Aarhus, Denmark) by the zone annealing technique from a titanium rod in a nitrogen atmosphere of $99.9 \%$ purity under a pressure of 2 $\mathrm{MPa}$ at a temperature of $2600^{\circ} \mathrm{C}$. Chemical analyses gave the following impurity content: oxygen ( $0.37 \%$ by weight), total metallic impurities (200 ppm by weight, mainly $\mathrm{Al}: 100 \mathrm{ppm}, \mathrm{Fe}: 60 \mathrm{ppm})$. The lattice parameter of the fcc crystal was $a=4.228 \AA[6]$.

The samples were cut along the (001) plane; the 
crystal was first oriented by the Laüe method. Then they were mechanically polished with diamond pastes of varied sizes $(8 \mu \mathrm{m}$ to $2 \mu \mathrm{m})$.

The samples were implanted perpendicularly to the surface with ${ }^{15} \mathrm{~N}^{+}$ions, and the implanted doses were $6 \times 10^{16}$ ions $/ \mathrm{cm}^{2}$ [7].

Then, as implanted specimens received thermal treatments in a graphite furnace, under a total nitrogen pressure of $1 \mathrm{~atm}$, at various temperatures from $700{ }^{\circ} \mathrm{C}$ to $1400{ }^{\circ} \mathrm{C}$. The samples were placed in the middle of the furnace into a graphite crucible, filled with titanium nitride powder in order to avoid sample contamination by graphite. Before the temperature rise, a vacuum of $2 \times 10^{-5}$ torr was established. While the temperature was raised $\left(300^{\circ} \mathrm{C} / \mathrm{h}\right)$, the vacuum level was maintained constant. All these processes reduced the furnace pollution caused by air, introduced when the samples were set in the furnace and emitted during heating of the graphite insulators of the furnace. When the diffusion temperature was reached, nitrogen (containing less than $1 \mathrm{ppm}$ impurities) under a pressure of $1 \mathrm{~atm}$ was introduced and the annealing time, at the diffusion temperature, was about 2 hours.

2.2 DIFFUSION PROFILE MEASUREMENTS. - The diffusion profiles were determined by Secondary Ion Mass Spectrometry (SIMS) with a CAMECA IMS $3 \mathrm{~F}$ analyser. The primary ion beam was made up of positive oxygen ions $\left(\mathrm{O}_{2}^{+}\right)$, accelerated under $10 \mathrm{kV}$ and focalized on the sample. The positive secondary ions were extracted by polarisation of the sample. All the analysis were made with positive secondary ions, because, for the same concentration, the intensity of negative nitrogen ions was weaker than the intensity of positive nitrogen ions. At the surface of the sample, oxygen scanning was carried out during the analysis to oxidize the titanium. Thus, the surface of the sample was saturated with oxygen, and the analysis of the titanium was easier. The ionic intensity, in number of counts per second vs. time, could be obtained for ions of 14, 15 and 46 masses. Therefore, the nitrogen 15 concentration variations $\left[{ }^{15} \mathrm{~N}\right]$ vs. time could be measured.

For the measurement of actual concentrations, a calibration factor $k$ was defined as the ratio of the implanted ion dose $N_{\mathrm{D}}$ and the area of the implanted initial profile $A$ calculated with arbitrary units (a.u.) for ionic intensities :

$$
k=N_{\mathrm{D}}\left({ }^{15} \mathrm{~N} \text { ions } / \mathrm{cm}^{3}\right) / A(\text { a.u. } \mathrm{cm}) .
$$

To obtain the nitrogen 15 concentration $\left[{ }^{15} \mathrm{~N}\right] v s$. the $x$ penetration, the crater method was used : by the primary ionic beam scanning, the ions hollowed out a crater and its depth varied vs. time. The secondary ionic intensity was proportional to the concentration of the elements in the eroded volume. The erosion rate was assumed to be constant, as was verified in the case of $\mathrm{C}$ implanted in $\mathrm{SiC}$ [8]. The depth of the craters was measured with a precision rugosimeter (Talystep). The precision of the measurements was $5 \%$.

2.3 THE CAlCulation OF Diffusion COEFFICIENTS. - The experimental initial profile after implantation is represented in figure 1. Except for the boundaries where there is a deviation from a Gaussian shape, the profile can be represented by the equation :

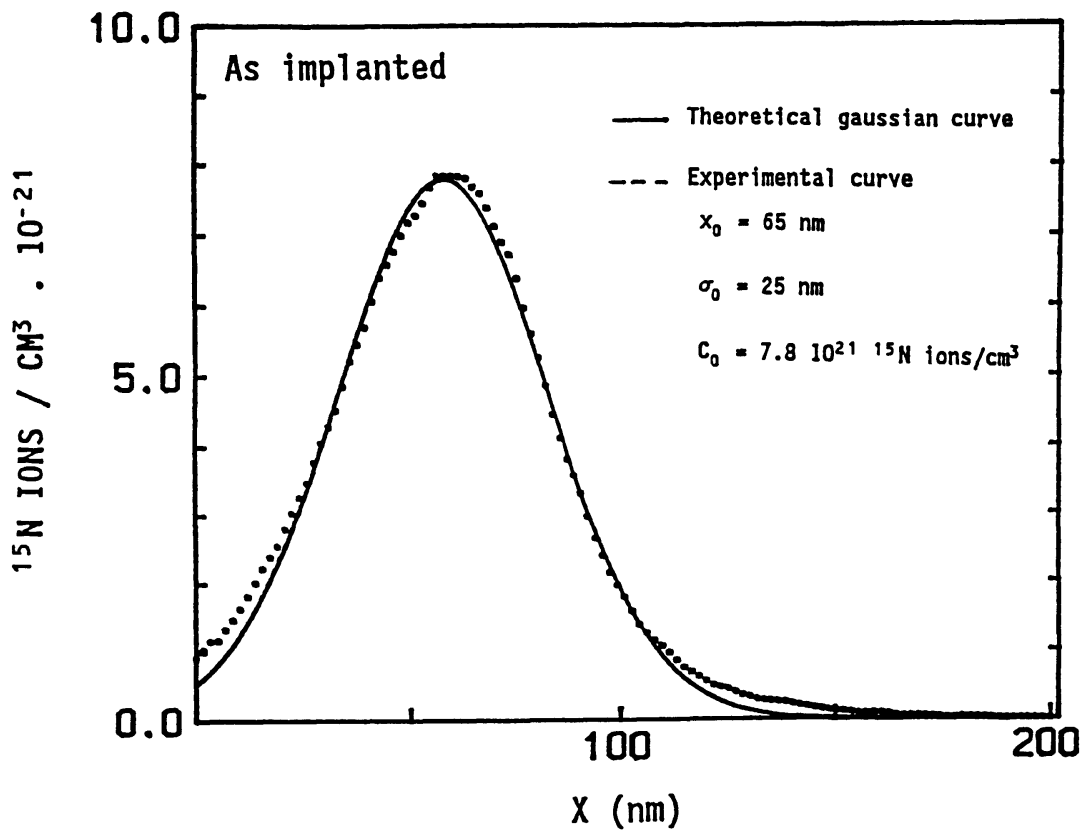

Fig. 1. $-{ }^{15} \mathrm{~N}$ concentration versus penetration $x$ profiles : fit of the experimental points with a Gaussian curve. 


$$
C(x, 0)=C_{0} \exp \left[-\frac{\left(x-x_{0}\right)^{2}}{2 \sigma_{0}^{2}}\right]
$$

where

$C_{0}=$ maximum concentration at the abscissa $x=x_{0}$

$\sigma_{0}=$ width at half-height of the Gaussian initial profile

$x_{0}=$ the depth of the maximum of the initial profile.

Several solutions were adopted in the case of a diffusion where the initial profile is Gaussian.

When it was supposed that the profile after diffusion remained Gaussian, Seidel and MacRae [9] derived a solution of the diffusion equation where there is no diffusion outside in a semi-infinite sample.

On the other hand, Meyer and Mayer [10] considered the case of a surface which acts as a perfect sink. Tajima et al. [11] applied a particular solution with the conditions that the annealing time is short enough to neglect the boundary conditions at the surface.

When the profile does not remain Gaussian, a mathematical solution is given by Schimko et al. [12] in the case where the surface acts as if it was totally transparent.

More recently, another solution was given by Ghez et al. [13], where they supposed that the surface was perfectly reflective.

In fact, it is very rare that the boundary conditions are very well-defined. Thus we chose as Meyer $e t$ al. [14] a compromise between these different cases, by using a coefficient $(\tau)$, taking into account that the surface acts neither as a perfectly transparent nor as a completly reflectivity plane. Then, the solution of Fick's second equation can be described by:

$$
\begin{aligned}
& C(x, t)= \\
& =\frac{C_{0} \sigma_{0}}{2 \sigma}\left[\exp -\frac{\left(x-x_{0}\right)^{2}}{2 \sigma^{2}}\left(1+\operatorname{erf} \frac{a^{2} x_{0}+x}{a \sigma \sqrt{2}}\right)-\right. \\
& \left.\quad-\tau \exp -\frac{\left(x+x_{0}\right)^{2}}{2 \sigma^{2}}\left(1+\operatorname{erf} \frac{a^{2} x_{0}-x}{a \sigma \sqrt{2}}\right)\right]
\end{aligned}
$$

where

$$
\begin{aligned}
& \sigma=\sqrt{\sigma_{0}^{2}+2 D t} \\
& a=\frac{\sqrt{2 D t}}{\sigma_{0}} .
\end{aligned}
$$

$\tau$ being what we call a transmission coefficient. When $\tau=+1$, it is the case of a perfectly transparent surface. Therefore we go back to the equation found by Schimko et al. [12].

When $\tau=-1$, the surface is perfectly reflective. We find the equation of Ghez et al. [13].

We should notice that if the terms with erf are neglected, the equations with Gaussian profiles after diffusion are once again found. Therefore, this equation is a rather general solution, in the case of a Gaussian initial profile.

Giving $\tau$ an adjusted value between -1 and +1 , the real conditions at the surface can be taken into account. In figure 2, the influence of the parameter $\tau$ $(-1 \leqslant \tau \leqslant+1)$ on the theoretical fitted curve is shown. This parameter is more effective near the surface.

The $C_{0}, x_{0}$ and $\sigma_{0}$ values were the characteristics

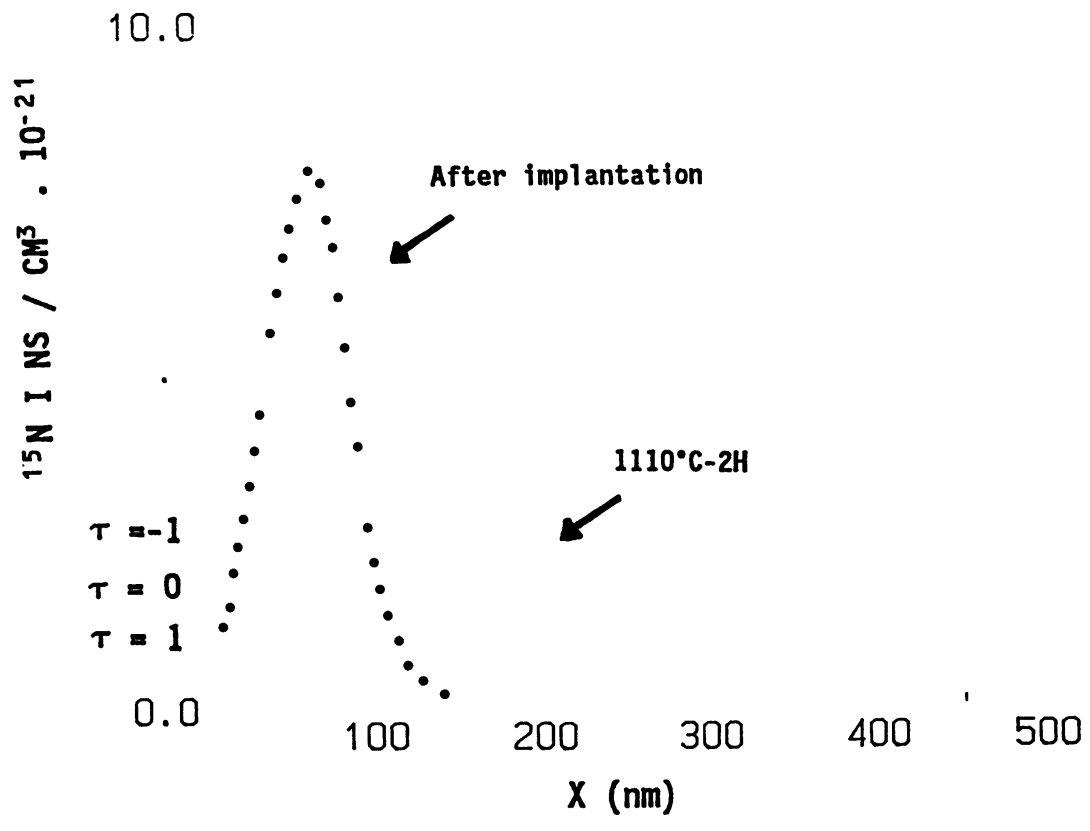

Fig. 2. - Influence of $\tau$ parameter $(-1 \leqslant \tau \leqslant+1)$ on the theoretical fitted curve. 
of the initial Gaussian. For the area near the surface, these values are in agreement with the L.S.S. (Lindhard, Scharff and Schiott) theory [15] (Tab. I). Thus, in the penetration range near the surface, for a diffusion coefficient $D$ and a transmission coefficient $\tau$ where both are determined, the curve $C(x)$ corresponding to the equation (2) can be obtained by calculation.

Table I. - Comparison between L.S.S. theory parameters for the layer near the surface and the experimental ones.

\begin{tabular}{|c|c|c|c|c|}
\hline $\begin{array}{c}E \\
(\mathrm{keV})\end{array}$ & $\begin{array}{c}x_{0 \text { th }} \\
(\mathrm{nm})\end{array}$ & $\begin{array}{c}x_{0 \exp } \\
(\mathrm{nm})\end{array}$ & $\begin{array}{c}\sigma_{0 \text { th }} \\
(\mathrm{nm})\end{array}$ & $\begin{array}{c}\sigma_{0 \exp } \\
(\mathrm{nm})\end{array}$ \\
\hline 50 & 64.8 & 59.8 & 23 & 25 \\
100 & 130 & 125 & 36 & 38 \\
\hline
\end{tabular}

On the other hand, deeper in the materials, a deviation from the Gaussian profile can be observed. This fact has often been described by several authors who have found an exponential profile for the tail of the implantation curve [16]. In this study, the deviation can better be described by an error function and its evolution after diffusion more correctly responds to an error function than an exponential function. To illustrate this assertion, the Argerf $C=f(x)$ curve (where Argerf function is the inverse function of erf) for a typical concentration profile is represented in figure 3 .

This curve is a straight line at the end of the profile.

In other terms, the as-implanted concentration profile exhibits two parts: one with a Gaussian profile and the another with an error function profile.

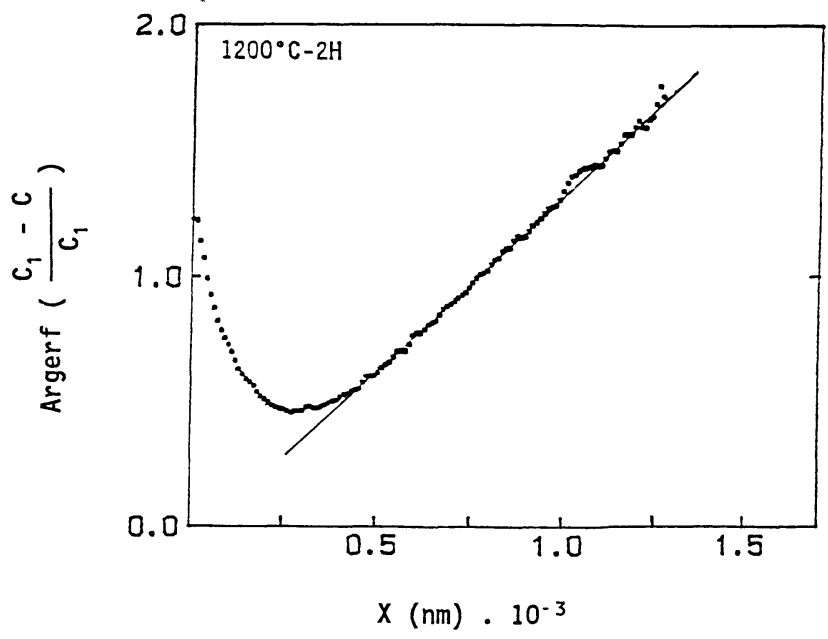

Fig. 3. - Curve Argerf $C=f(x)$.
Therefore, an abscissa $x_{1}$ (corresponding to the concentration $C_{1}$ ) can empirically be determined, from which the error function is well-adapted.

Taking into consideration the following boundary conditions :

$$
\begin{array}{rlrl}
t>0 & x=x_{1} & C & =C_{1} \\
& x \rightarrow+\infty & C & =0
\end{array}
$$

the following solution is adopted :

$C(x, t)=C_{1}\left[1-\operatorname{erf}\left(\frac{x-x_{1}}{2 \sqrt{D t}}\right)\right]$ for $x \geqslant x_{1}$.

Equation (2) allows us to determine a diffusion coefficient $D_{1}$ and equation (5), a diffusion coefficient $D_{2}$.

The values of $C_{1}$ (the concentration corresponding to the $x_{1}$ abscissa) and $x_{1}$ (characterizing the deviation from the Gaussian) vary with the temperature of the annealing.

In this manner, two diffusion coefficients have to be chosen for a good adjustment of the entire curve. This will be discussed in the following section.

We obtained for each temperature two diffusion coefficients $D_{1}$ or $D_{2}$, depending on whether the $x$ abscissa is inferior or superior to $x_{1}$ previously defined.

Another procedures based on any initial profile, such as that proposed by Ghez et al. [17] or Tarento [18] existed. This latter method has been tested but does not allow the adjustment of the entire curve.

\section{Results and discussion.}

The diffusion coefficient $D_{1}$ allowing the best fit of the theoretical curve with the experimental one obtained after diffusion, was determined by successive approximations.

In figure 4, an example of an adjustment of the diffusion profiles is represented. The values of the diffusion coefficients $D_{1}$ and $D_{2}$ are shown in table II.

A correction for annealing was made [20], using the equation:

$$
\Delta t=\exp \frac{Q}{R T_{0}} \int_{293}^{T_{0}} \exp \left(\frac{-Q}{R T}\right) \frac{\mathrm{d} t}{\mathrm{~d} T(t)} \mathrm{d} T
$$

and $\Delta t=t_{\mathrm{c}}-t_{0}$

where $t_{0}$ is the annealing time, $t_{\mathrm{c}}$ the corrected annealing time, $Q$ the activation energy at the time $t_{0}, T_{0}$ the temperature of the annealing and $\frac{\mathrm{d} T(t)}{\mathrm{d} t}$ the heating or cooling rate.

The influence of this correction on the diffusion coefficients is insignificant and does not change the values of the diffusion coefficients (for example, for $T=1000^{\circ} \mathrm{C}$ and $t_{0}=2 \mathrm{~h}, D=5.7 \times 10^{-16} \mathrm{~cm}^{2} / \mathrm{s}$, 


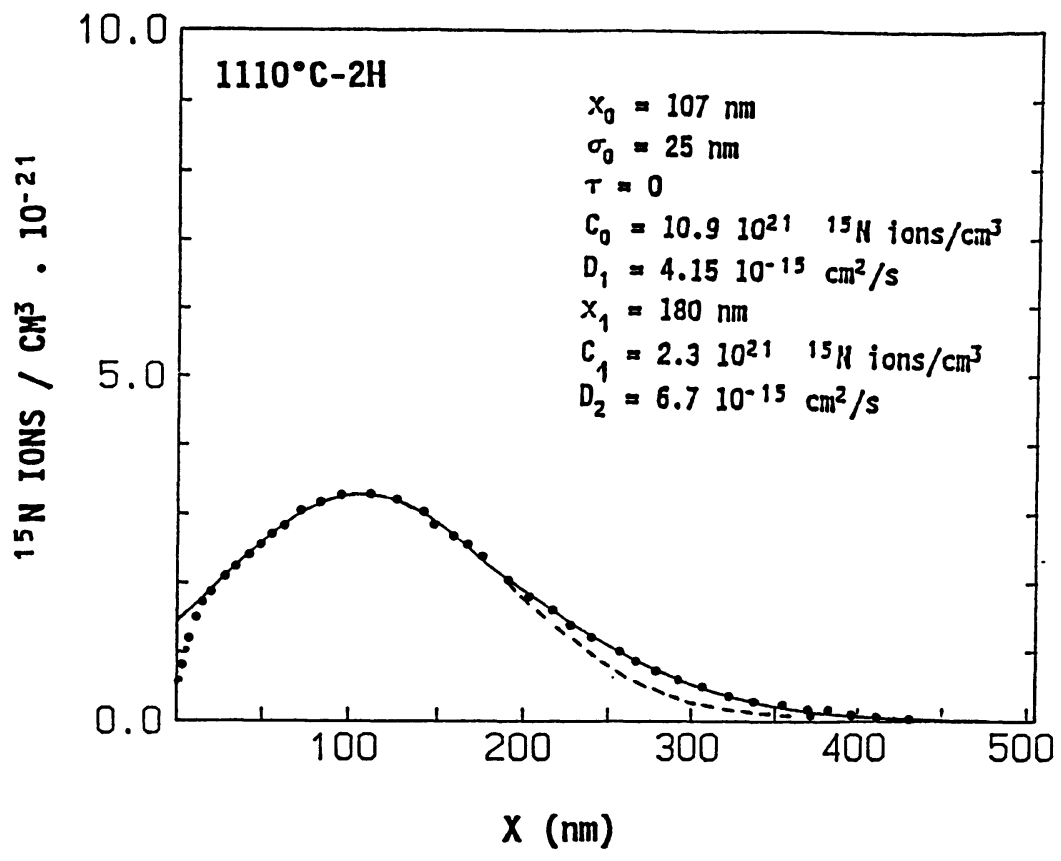

Fig. 4. - Example of fit giving the diffusion coefficients.

Table II. - Calculated values of the diffusion coefficients $D_{1}$ and $D_{2}$.

\begin{tabular}{|r|l|l|}
\hline$T(\mathrm{C})$ & $D_{1}\left(\mathrm{~cm}^{2} / \mathrm{s}\right)$ & $D_{2}\left(\mathrm{~cm}^{2} / \mathrm{s}\right)$ \\
\hline 850 & $7.3 \times 10^{-17}$ & $1.33 \times 10^{-15}$ \\
900 & $1.53 \times 10^{-16}$ & $1 \times 10^{-15}$ \\
1000 & $5.7 \times 10^{-16}$ & $1.44 \times 10^{-15}$ \\
1085 & $3.11 \times 10^{-15}$ & $7.94 \times 10^{-15}$ \\
1100 & $3.1 \times 10^{-15}$ & $4.5 \times 10^{-15}$ \\
1110 & $4.15 \times 10^{-15}$ & $6.7 \times 10^{-15}$ \\
1150 & $8 \times 10^{-15}$ & $2.13 \times 10^{-14}$ \\
1230 & $1.58 \times 10^{-14}$ & $3.68 \times 10^{-14}$ \\
1300 & $3.6 \times 10^{-14}$ & $6.85 \times 10^{-14}$ \\
1400 & $1.51 \times 10^{-13}$ & $2.31 \times 10^{-13}$ \\
\hline
\end{tabular}

$t_{\mathrm{c}}=2.1 \mathrm{~h}$ and $D_{\mathrm{c}}=5.3 \times 10^{-16} \mathrm{~cm}^{2} / \mathrm{s}$, where $D_{\mathrm{c}}$ is the corrected diffusion coefficient).

fusion coefficients are approximately aligned along a straight line: the diffusion coefficients can be estimated as corresponding to the equations :

$$
\begin{aligned}
D_{1}=4 \times 10^{-7}\left(\mathrm{~cm}^{2} / \mathrm{s}\right) \times & \\
& \times \exp [-2.26 \pm 0.2(\mathrm{eV} / \mathrm{at}) / k T] \\
D_{2}=1.3 \times & 10^{-8}\left(\mathrm{~cm}^{2} / \mathrm{s}\right) \times \\
& \times \exp [-1.65 \pm 0.2(\mathrm{eV} / \mathrm{at}) / k T] .
\end{aligned}
$$

Note that for $x<x_{1}$, the nitrogen concentration is high because of the implantation. Thus, we can

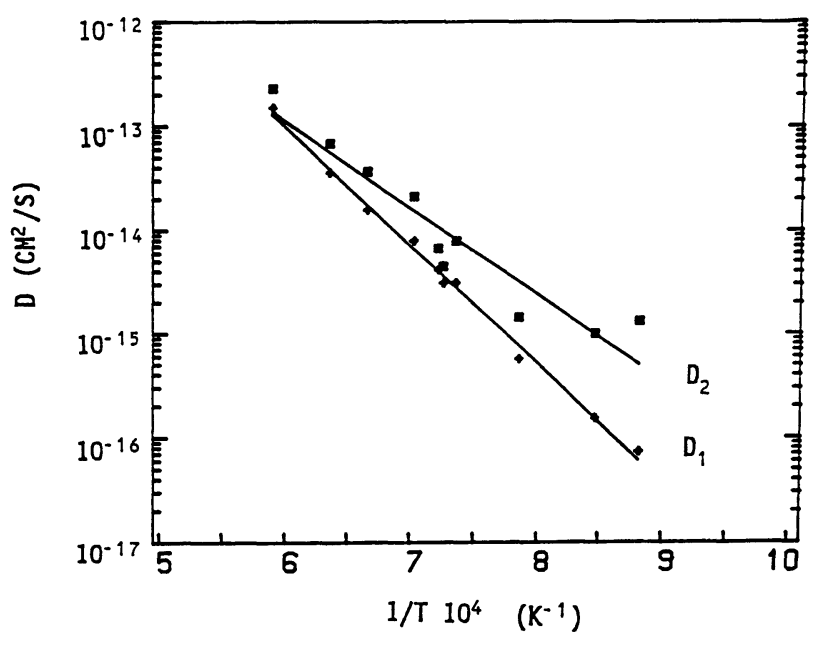

Fig. 5. - Arrhenius curve $\log D=f\left(\frac{1}{T}\right)$.

suppose that after thermal treatment, the thermodynamic equilibrium is reached, and that in this area, the nitrogen vacancy concentration is weak, while it is very high in depth where the composition draws near $\mathrm{TiN}_{0.82}$.

The diffusion coefficients $D_{2}$ are higher than $D_{1}$ and this is in agreement with a vacancy diffusion mechanism.

However, we notice the tendency of $Q_{2}$ to be lower than $Q_{1}$, which would be the result of a different diffusion mechanism. The possibility of the formation of divacancies, in the area of high nitrogen vacancy concentration is excluded, because according to Adda et al. [19], the activation energy $Q_{2}$ would be higher than $Q_{1}$, and this is not the case. 
Nevertheless, in the layer near the surface, the sample composition is nearly stoichiometric and the thermal vacancies are predominant. An additional term of formation, which will be $\Delta H_{\mathrm{f}}=Q_{1}-Q_{2}=0.6 \mathrm{eV} /$ at can explain the difference between the activation energies.

That the vacancy concentration is higher, deeper in the material, probably involved a diffusion in a chemical concentration gradient. Thus, the diffusion coefficients obtained are rather chemical diffusion coefficients than self-diffusion coefficients.

To directly reach self-diffusion coefficients, other investigations are in progress based on the gas-solid exchange.

Previous indirect estimations from the nitride layer growth on titanium [21-23] gave results higher than ours by about 4 orders of magnitude.

In fact, it seems that according to Wood et al. [21], in addition to $\operatorname{Ti}(\alpha), \operatorname{Ti}(\beta)$ and $\delta$-TiN phases, the $\varepsilon$ phase with a composition near to $\mathrm{Ti}_{2} \mathrm{~N}$ was formed near the surface, up to $1700{ }^{\circ} \mathrm{C}$. In the earlier studies [22, 23], this fact did not take into account.

Thus the previous results probably did not correspond to the $\delta$ phase of the nitride and their measurements were not the diffusion coefficients in the $\delta$ phase.

Our results seem to correspond really to the diffusion in the $\delta$ phase, although many difficulties appear for a diffusion study by the implantation method.

Our affirmation was supported by experiments in progress, based on the method of the isotopic gas solid exchange which leads to results of the same order of magnitude than those presented in this study.

\section{Conclusion.}

A very different method than usual was used in this study. By the implantation technique and SIMS analyses, a direct determination of the concentration profile evolution was interpreted in terms of diffusion.

Our results are lower than previous data but correspond to a diffusion in a single phase material and not in multiphased nitride layers in growth, the boundary concentration of which, are not directly known and which can present diffusion short circuits (microcracks, grain boundaries, pores...).

Taking into account the large variation of concentration, the diffusion coefficients obtained in this investigation are rather chemical diffusion coefficients and have to be compared to the self diffusion coefficients determined by a direct analysis of the concentration profiles, by use of the classical method of the gas solid exchange, often used in the case of the oxides.

\section{Acknowledgments.}

The authors gratefully acknowledge the support of the Ministère de la Recherche by a collaboration with Céramiques Techniques Desmarquest France.

We thank C. H. de Novion (C.E.N. Saclay, France) and A. N. Christensen (Aarhus University, Denmark) for the gift of titanium nitride single crystals ; J. Chaumont and O. Kaïtasov (Orsay University, France) for the ionic implantations; $\mathbf{M}$. Miloche (C.N.R.S. Bellevue, France) for the S.I.M.S. analyses.
[1] Kuzenkova M. A. and Kislyi P. S., Poroshkovaya Metallurgiya 98 (1971) 52-56.

[2] Uematsu K., Kieda N., Sakurai O., Mizutani N. and Kato M., Yogyo Kyokai Shi 90 (1982) 10, 597.

[3] Sato S., Shinozaki K., Uematsu K., Mizutani N. and KATO K., Yogyo Kyokai Shi 89 (1981) 7, 381.

[4] Yamada Tetsuo, Shimada Masahiko and Koisumi Mitsue, Yogyo Kyokai Shi 89 (1981) 11, 621.

[5] Yamada T., Shimada $M$. and Koizumi M., Ceramic Bulletin 59, 6 (1980).

[6] Priem T., Beuneu B., De Novion C. H. and Christensen A. N., Solid State Commun. 63 (1987) 929-932.

[7] Implantations were carried out the Centre de Spectrométrie Nucléaire et de Spectrométrie de Masse (Université d'Orsay, France).

[8] LI J. Thèse Orsay (1990).
[9] Seidel T. E. and MAcRae A. U., Trans. Metall. Soc. AIME 245 (1969) 491.

[10] Meyer O. and Mayer J. W., J. Appl. Phys. 41 (1970) 4166.

[11] TAJima Y., KiJima K. and Kingery W. D., J. Chem. Phys. 77 (1982) 2592-2598.

[12] Schimko R., Schwarz G. and Rogge K., Phys. State Sol. (a) 28 (1975) K163.

[13] Ghez R., Oehrlein G. S., Sedgwick T. O., MoreheAD F. F. and LeE Y. H., Appl. Phys. Lett. 45 $\mathrm{n}^{\circ} 8$ (1984).

[14] Meyer M., Barbezat S., El Houch C. and Talon R., J. Phys. Colloq. 41 (1980) C6-327.

[15] SMITH B. J., A.E.R.E. Report, R6660 (1971).

[16] Dearnaley G., Freeman J. H., Nelson R. S. and STEPHEN J., Series Defects in crystalline solids (North Holland) Vol. 8 (1973).

[17] Ghez R., Fehribach J. D. and Oehrlein G. S., J. Electrochem. Soc. 132 (1985) 2759. 
[18] Tarento R. J., Revue Phys. Appl. 24 (1989) 11.

[19] AddA Y. et Philibert J., La diffusion dans les solides (Paris) 1966.

[20] Philibert J., Diffusion et transport de matière dans les solides (Les Editions de Physique) 1985.
[21] Wood F. W. and PaAsche O. G., Thin Solid Films 40 (1977) 131.

[22] WASILEWSKi R. J. and KeHL G. L., J. Inst. Metals 83 (1954) 94.

[23] Eremeev V. S., Ivanov Yu M. and Panov A. S., Izv. Akad. Nauk. SSSR Met. 4 (1969) 262. 